\title{
UNA ETAPA EN LA RUTA MOGADOR-CANARIAS. CERÁMICA ROMANA EN LANZAROTE Y SU RELACIÓN CON LOS HALLAZGOS SUBMARINOS
}

\author{
A STAGE IN THE MOGADOR-CANARY ISLANDS ROUTE. ROMAN POTTERY \\ IN LANZAROTE AND ITS RELATIONSHIP WITH UNDERWATER FINDS
}

\author{
por \\ ALFREDO MEDEROS MARTÍN * \\ GABRIEL ESCRIBANO COBO **
}

RESUMEN El reciente descubrimiento de cerámicas a torno en un yacimiento terrestre de Lanzarote, con fechas entre 30-50 D.C. al 420 D.C., ha sido atribuido a ánforas romanas con procedencias de la Bética, Campania y Túnez. Simultáneamente, se consideran todos los hallazgos anfóricos subacuáticos de las Islas Canarias como de los siglos XVI-XVII D.C. Este trabajo pretende ofrecer un análisis detallado de la estratigrafía del yacimiento de El Bebedero (Lanzarote), discutir los argumentos con los que se rechaza el origen romano de los hallazgos subacuáticos y poner en evidencia la estrecha relación entre Mogador y Canarias.

ABSTRACT The recent discovery of wheel-made pottery in a terrestrial location of Lanzarote, with dates between 30-50 A.D. to 420 A.D., have been attributed to roman amphorae with origin of the Baetica, Campania and Tunisia. Simultaneously, they think that all the underwater amphorae from the Canary Islands have a chronology between the 16th and 17th centuries A.D. The aim of this paper is an careful stratigraphical analysis of the archaeological site El Bebedero (Lanzarote), offer a discusion about the arguments that support the reject the roman origin for the underwater amphorae and emphasize the relationship between Mogador and the Canary Islands.

\section{INTRODUCCIÓN}

Uno de los argumentos más evidentes que han servido para rechazar algún tipo de contacto entre las Islas Canarias y el mundo romano limítrofe, Andalucía Occidental y Norte de Marruecos, ha sido la permanente

\footnotetext{
* Becario postdoctoral de la Dirección General de Investigación Científica y Técnica, Ministerio de Educación y Ciencia en el Institute of Archaeology. University of Oxford.

** Programa de Doctorado del Departamento de Prehistoria, Antropología e Historia Antigua, Universidad de la Laguna
} 
ausencia de cerámica romana en las monografías y artículos publicados sobre yacimientos terrestres excavados de las Islas Canarias.

La primera vez que se altera esta situación fue a raíz de las últimas campañas de excavación en la Cueva Pintada (Gáldar, Gran Canaria), que forma parte del gran poblado aborigen de Gáldar, tradicionalmente considerado el yacimiento más importante de la isla.

Pese a las expectativas despertadas tras su anuncio en prensa por el director de las excavaciones, $\mathrm{C}$. Martín de Guzmán (en Ossorio 1990: 38), quien citaba la presencia de "cerámicas de origen tardorromano, otras árabes, y también cerámicas mediterráneas medievales trabajadas a torno", a posteriori, los informes arqueológicos no confirmaron tal supuesto, puesto que sólo se habla de cerámica a torno datada entre los ss. XI-XII D.C. (Martín de Guzmán y Onrubia 1990: 145), en gran parte vidriadas, que con las nuevas dataciones cubrirían los siglos X-XIII D.C. (Martín de Guzmán et alii 1992: 172, 194).

La posterior revisión estratigráfica del nivel correspondiente les llevará a asumir que el nivel susodicho no se trataba de una reutilización de una casa de cantos de "toba", o estructura 1, sino de un depósito de arrastre de ladera, el cual fue en su momento objeto de una valoración quizás "en exceso apresurada" (Martín de Guzmán et alii 1994: 31). El estudio de la cerámica a torno del yacimiento ha confirmado esta revisión cronológica, detectándose moldes para la fabricación de panes de azúcar, al menos de fines del siglo XV, cuerda seca, loza dorada, y dos mayólicas españolas, loza blanca (Columbia Plain) y del tipo Isabela Polychrome, entre otras, que hablan claramente de cerámicas coetáneas o inmediatamente posteriores a la conquista (Onrubia et alii e.p.).

Este precedente no favoreció la acogida científica de la presentación en la prensa del hallazgo de cerámicas romanas en el poblado de El Bebedero (Teguise, Lanzarote) (fig. 1), donde se hablaba del descubrimiento de 20 fragmentos cerámicos, supuestamente asociables a ánforas desde el siglo I a.C. hasta quizás el siglo II d.C., procedentes de la Península Ibérica (Andalucía), Norte de África (Túnez) e Italia (Campania) (Ideapress 1993: 17). No obstante, la publicación poco después del informe de la campaña de 1987 (Atoche 1993: 10,17 fig. 4/3) reafirmaba la presencia en el estrato IV de cerámicas a torno correspondientes a grandes recipientes romanos asignables "a los primeros momentos de la época imperial" y "a época tardorromana", asociados a artefactos metálicos de bronce y una cuenta de collar de pasta vítrea.

Felizmente, aunque ya conocíamos previamente la monografía de los resultados de la primera campaña de excavaciones de 1985 en El Bebedero (Atoche et alii 1989), de la que proceden algunas de estas cerámicas, antes de la publicación de la monografía detallada con las campañas de 1987 y 1990, se ha adelantado un volumen sobre todas las cerámicas a torno halladas en las excavaciones de El Bebedero (Atoche et alii 1995) que pone en evidencia el deseo de rigor científico por parte de los investigadores y, simultáneamente, permite a la comunidad arqueológica valorar en detalle esta notable aportación.

\section{LA CRONOLOGÍA ABSOLUTA DE EL BEBEDERO}

En general, el dato más significativo de las determinaciones actualmente disponibles (Tabla 1) es la relativa homogeneidad de las mismas que señalan claramente que se mueven entre ca. 30-50 D.C. hasta ca. 420 D.C., esto es entre los siglos I-V D.C.

Una cuestión más delicada es la falta de homogeneidad interna de la serie. Si nos atenemos a los datos contextuales sobre la estratigrafía que conocemos de las muestras, aunque carecemos de información sobre el tipo de muestras que han sido datadas, ordenándolas de acuerdo con su procedencia estratigráfica serían: contacto nivel 5-4 (70 D.C.), nivel 4 base (215 D.C.), nivel 4 (30-50 D.C., 120 D.C.), contacto nivel 4-3 (420 D.C.). En general se aprecia que las dos determinaciones obtenidas por sistemas convencionales son ligeramente más antiguas que la scrie más reciente procesada mediante AMS. El anuncio de una serie aún 
más amplia de dataciones procesándose en el laboratorio de Groningen (Atoche et alii 1995: 33) ayudará a encuadrar mejor la cronología interna de cada nivel.

\begin{tabular}{|c|c|c|c|c|c|c|c|c|}
\hline Yacimiento & Muncipio-Isla & B.P. & \pm & a.C.-d.C. & $\begin{array}{l}\text { máx. } \\
\text { CAL }\end{array}$ & $\begin{array}{c}\text { CAL } \\
\text { AC-DC }\end{array}$ & $\begin{array}{l}\min . \\
\text { CAL }\end{array}$ & $\begin{array}{l}\mathrm{n}^{o} \text { y tipo de } \\
\text { muestra }\end{array}$ \\
\hline $\begin{array}{c}\text { El Bebedero. } \\
\text { Contacto Nivel } \\
\text { IV y V }\end{array}$ & Teguise, Lanzarote & 1950 & 60 & 0-1 d.C. & $50 \mathrm{AC}$ & $70 \mathrm{DC}$ & 224 DC & GrN-15762/? \\
\hline $\begin{array}{l}\text { El Bebedero. } \\
\text { Base Nivel IV }\end{array}$ & Teguise, Lanzarote & 1840 & 30 & 110 d.C. & $89 \mathrm{DC}$ & $215 \mathrm{DC}$ & 312 DC & GrN-15804/? \\
\hline $\begin{array}{l}\text { El Bebedero. } \\
\text { Nivel IV }\end{array}$ & Teguise, Lanzarote & 1980 & 140 & 30 a.C. & $368 \mathrm{AC}$ & $\begin{array}{l}30 \text { DC } \\
40 \\
50\end{array}$ & $382 \mathrm{DC}$ & GrN-19194/? \\
\hline $\begin{array}{l}\text { El Bebedero. } \\
\text { Nivel IV }\end{array}$ & Teguise, Lanzarote & 1895 & 120 & 55 d.C. & $169 \mathrm{AC}$ & $120 \mathrm{DC}$ & $414 \mathrm{DC}$ & GrN-19195/? \\
\hline $\begin{array}{c}\text { El Bebedero. } \\
\text { Contacto Nivel } \\
\text { III y IV }\end{array}$ & Teguise, Lanzarote & 1635 & 90 & 315 d.C. & $231 \mathrm{DC}$ & $420 \mathrm{DC}$ & $625 \mathrm{DC}$ & GrN-19192/? \\
\hline $\begin{array}{l}\text { El Bebedero. } \\
\text { Nivel IV }\end{array}$ & Teguise, Lanzarote & - & - & - & - & - & - & $\begin{array}{l}\text { GrN-13754 } \\
\text { poco carbón }\end{array}$ \\
\hline
\end{tabular}

Tabla 1. Determinaciones obtenidas en el poblado de El Bebedero por sistemas convencionales, las dos primeras, y Espectroscopía de Masas de Aceleración o A.M.S. (Accelerator Mass Spectrometry). Fuentes: Atoche et alii (1989: 204 y 1995: 34). Dataciones calibradas a partir de Cal 3.0.3.

La cronología del estrato 3 resulta más frágil, no sólo porque la fecha del 420 D.C. fue tomada "en la base del estrato III en contacto con el estrato IV" (Ib. 1995: 34), sino también debido a que según sus excavadores dicho estrato III, o fase 2 del poblado, situaría su inicio en el siglo IV d.C. y su momento final "sin grandes problemas en los primeros años del Siglo XV, en concreto entre los años 1402 y 1404" (Ib. 1995: 36), fase de unos 1000 años que ya se defendió en la primera monografía (Ib. 1989: 210).

La presencia de fragmentos a torno vidriados de un mismo recipiente que se reparten en el nivel 3 (fragmento 22), nivel 2 (frag. 20), nivel 1 (frag. 18) y nivel superficial (frag. 27), implica algún tipo de remoción superficial, y el análisis del fragmento 18 (muestra LA 18) (Ib. 1995: 62) les lleva a considerar estos fragmentos "cerámicas del siglo ¿XV?, con una influencia hispano-musulmana".

\section{LAS MUESTRAS ANALIZADAS DE LAS CERÁMICAS A TORNO DE EL BEBEDERO}

El principal problema que se aprecia en la serie de cerámicas a torno del yacimiento El Bebedero es la total ausencia de formas tipológicamente definitorias que faciliten su identificación como cerámica romana, con excepción de un cuello. La inexistencia de cualquier tipo de fragmento de Terra sigillata en El Bebedero tampoco ayuda al encuadre de estas cerámicas a torno.

Un análisis de la distribución de las cerámicas a torno dentro de estratigrafía del yacimiento resulta particularmente reveladora. Dentro de los posibles recipientes definidos por los excavadores, la no coherencia en la distribución dentro de cada estrato es patente. Salvo el contenedor cerámico 8 del estrato III y los contenedores 3,13 y 14 del estrato IV, todos los restantes recipientes cerámicos con más de un fragmento se reparten en varios estratos, caso de los números 1, 2, 3, 9, 10, 11 y 15 (Tabla 2). Sin embargo, se trata 
de una adscripción visual por parte de Atoche et alii (1995) a posibles contenedores, ya que no se disponen de análisis de todos ellos.

Si contrastamos los datos de distribución de materiales con la estratigrafía, se aprecia que el estrato dominante es el IV, que concentra el $67.15 \%$ de la cerámica a torno. En la descripción sedimentaria queda claro que el estrato V es muy poco compacto frente a la solidez del estrato IV. Por el contrario, la transición del estrato III al IV resulta mucho menos clara, porque cuando "nos aproximamos al inicio del estrato IV, la arcilla se hace cada vez más compacta, resultando en ocasiones muy difícil de extraer" (Atoche et alii 1989: 24-25). Además, debemos tener en cuenta la poco representativa muestra cerámica del estrato V, en el cual, a medida que profundizamos, acaba desapareciendo la cerámica, y el hecho que los excavadores unifican los estratos V y IV para formar la fase arqueológica 1.

Estos datos estratigráficos y la relativamente heterogénea distribución de la cerámica a torno insinúan que ante lo que aparentemente nos encontramos es con un único nivel arqueológico, que no sedimentario, que integraría el inicio del estrato III, el IV y el final del V, salvo que se reconozca la presencia de cierto número de intrusiones, caso del contenedor cerámico 3 cuyos fragmentos están presentes en los estratos I y IV, si es que todos pertenecen al mismo contenedor. Simultáneamente, cabría añadir la existencia de intrusiones desde los estratos superiores, superficial, I y II, correspondientes al nivel de cultivo subactual, hacia el estrato III, tal como insinúa el contenedor vidriado cerámico 2 , con fragmentos repartidos en los estratos superficial, I, II y III (Tabla 2).

\begin{tabular}{|c|c|c|c|c|c|c|c|}
\hline $\begin{array}{l}\text { ESTRATOS } \\
\text { POTENCIA }\end{array}$ & PERFIL & $\begin{array}{c}\text { SUPERF. } \\
0.01\end{array}$ & $\begin{array}{c}\text { I } \\
0.27\end{array}$ & $\begin{array}{c}\text { II } \\
0.11-0.16\end{array}$ & $\begin{array}{c}\text { III } \\
0.19-0.24\end{array}$ & $\begin{array}{c}\text { IV } \\
0.45-0.53\end{array}$ & $\begin{array}{c}\mathbf{V} \\
0.35\end{array}$ \\
\hline $\mathbf{N}^{\circ}$ FRAGMENTOS & 1 & 1 & 3 & 1 & 17 & 47 & 1 \\
\hline CONTENEDOR 1 & $1(17)$ & & $1(7)$ & & & & \\
\hline CONTENEDOR 2 & & $1(27)$ & $1(\mathbf{1 8})$ & $1(20)$ & $1(22)$ & & \\
\hline CONTENEDOR 3 & & & $1(19)$ & & & $3(2,14,26)$ & \\
\hline CONTENEDOR 4 & & & & & $1(\mathbf{8})$ & & \\
\hline CONTENEDOR 5 & & & & & $1(23)$ & & \\
\hline CONTENEDOR 6 & & & & & $1(28)$ & & \\
\hline CONTENEDOR 7 & & & & & $1(29)$ & & \\
\hline CONTENEDOR 8 & & & & & $2^{*}(15,24)$ & & \\
\hline CONTENEDOR 9 & & & & & $2(1,16 a)$ & $5(3,10,11,16 b, 32)$ & \\
\hline CONTENEDOR 10 & & & & & $1(30)$ & $4(4,9,25,40)$ & \\
\hline CONTENEDOR 11 & & & & & $2(21,31)$ & $3(5,36,37)$ & \\
\hline CONTENEDOR 12 & & & & & & $1(12)$ & \\
\hline CONTENEDOR 13 & & & & & & $3^{*}(13,38,41)$ & \\
\hline CONTENEDOR 14 & & & & & & $2 *(33,35)$ & \\
\hline CONTENEDOR 15 & & & & & & $2(34,39)$ & $1(6)$ \\
\hline
\end{tabular}

Tabla 2. Distribución de la cerámica a torno en la estratigrafía de El Bebedero. Los fragmentos se unifican según pertenezcan a un posible mismo recipiente cerámico. La primera cifra corresponde al número de fragmentos y la segunda, inserta entre paréntesis, al número que individualiza cada fragmento a torno. En negrilla los fragmentos con lámina delgada que confirman que 34, 39 y 6 pertenecen al mismo recipiente. Los fragmentos del 16a y 16b casan entre ellos. Ambos casos ratifican la presencia de intrusiones o de un único nivel arqueológico. Se destacan con un asterisco contenedores con más de un fragmento localizados en el mismo estrato, lo que sucede sólo en tres ocasiones: números 8,13 y 14 . 
La opción analítica elegida por el equipo investigador de El Bebedero ha sido la realización de láminas delgadas de un alto número de muestras, única posible dada la falta de formas tipológicamente diagnósticas, para tratar de correlacionarlas con la serie más amplia de muestras analizadas de ánforas publicada por Peacock y Williams (1985) y, en base a sus similitudes, asignar cada fragmento analizado a una posible ánfora (Tabla 3).

Un problema de esta estrategia de investigación deriva del limitado número de análisis petrográficos disponibles de ánforas romanas, ya que en otras regiones, como la Península Ibérica, no es habitual demostrar que se trata de cerámicas romanas y se disponen de series a torno amplias. Tal como reconocen los autores, el análisis petrográfico que realizaron de una Almagro 51C, procedente del Pecio Cabrera III, no es coincidente con la muestra publicada por Peacock y Williams (1985: 133, fig. 63). Sin embargo, "este aspecto no debe influir en su clasificación tipológica, ya que es frecuente que ánforas correspondientes a una misma forma se fabricaran en alfares diferentes" (Atoche et alii 1995: 60). La cuestión es cómo resolver este problema en El Bebedero, donde no disponemos de formas reconstruibles.

\begin{tabular}{|c|c|c|c|c|c|}
\hline Muestra & Estrato & Grupo & $\begin{array}{l}\text { Composición } \\
\text { mineralógica }\end{array}$ & Procedencia & Tipo de ánfora asignada \\
\hline LA 2 & IV & 1 & $\begin{array}{l}\text { cuarzo, calcáreas (calizas } \\
\text { micríticas), cuarcitas }\end{array}$ & Túnez & Clase 40/Benghazi MR 1 \\
\hline LA 14 & IV & 1 & $\begin{array}{l}\text { cuarzo, calcáreas (calizas } \\
\text { micríticas), cuarcitas }\end{array}$ & Túnez & Clase 40/Benghazi MR 1 \\
\hline $\begin{array}{l}\text { LA } 8 \\
\text { pivote }\end{array}$ & III & 2 & $\begin{array}{l}\text { cuarzo, feldespato } \\
\text { (sanidina), volcánicas }\end{array}$ & Campania & Clase 3-5/Dressel 1A-C \\
\hline LA 40 & IV & 2 & $\begin{array}{l}\text { cuarzo, feldespato } \\
\text { (sanidina), volcánicas }\end{array}$ & Campania & Clase 3-5/Dressel 1A-C \\
\hline LA 6 & $\mathrm{~V}$ & 9 & $\begin{array}{l}\text { calcáreas, cuarzo, } \\
\text { volcánicas }\end{array}$ & Campania & Clase 3-5/Dressel 1A-C \\
\hline LA 34 & IV & 9 & $\begin{array}{l}\text { calcáreas, cuarzo, } \\
\text { volcánicas }\end{array}$ & Campania & Clase 3-5/Dressel 1A-C \\
\hline LA 39 & IV & 9 & $\begin{array}{l}\text { calcáreas, cuarzo, } \\
\text { volcánicas }\end{array}$ & Campania & Clase 3-5/Dressel 1A-C \\
\hline LA 11 & IV & 3 & micaesquistos, graníticas & $\begin{array}{l}\text { Sierra Morena, } \\
\text { Guadalquivir, } \\
\text { Sistema Bético }\end{array}$ & $\begin{array}{c}\text { Clase 26/Dressel 23 } \\
\text { ¿Clase 25/Dressel 20? } \\
\text { ¿Clase 23/Almagro 51C? }\end{array}$ \\
\hline $\begin{array}{l}\text { LA } 16 \\
\text { cuello }\end{array}$ & III-IV & 3 & micaesquistos, cuarcitas & $\begin{array}{l}\text { Sierra Morena, } \\
\text { Guadalquivir, } \\
\text { Sistema Bético }\end{array}$ & $\begin{array}{c}\text { Clase 26/Dressel } 23 \\
\text { ¿Clase 25/Dressel 20? } \\
\text { ¿Clase 23/Almagro 51C? }\end{array}$ \\
\hline LA 32 & IV & 8 & cuarzo, micaesquistos & Guadalquivir & $\begin{array}{l}\text { Clase 20/Dressel } 14 \\
\text { Clase 25/Dressel } 20\end{array}$ \\
\hline
\end{tabular}

Tabla 3. Distribución sintética de las muestras de cerámica romana de El Bebedero (LA=Lanzarote), analizadas en P. Atoche et alii (1995: 48-61, 113-121). La Clase 40 (Ib. 1995: 48) corresponde a la Benghazi MR 1 (Peacock y Williams 1985: 175-176) y no a la Africana I pequeña, clase 33, o la Africana II grande, clase 34 (Ib. 1985: 153-157), por lo que no acabamos de comprender la relación gráfica que se plantea con la Africana I (Atoche et alii 1995: portada) o Africana I-II (Ib. 1995: 72, fig. 6), y que les lleva a apuntar una procedencia tunecina a las muestras LA 2 y 14, propias de las Africana I-II, cuando la Benghazi MR 1, presumiblemente, procede de la Tripolitania. 
Aunque a primera vista la correlación mineralógica es correcta, podrían plantearse algunas dudas respecto a las tres procedencias propuestas: Guadalquivir, Italia y Túnez. El valle del Guadalquivir, y en concreto particularmente los talleres de Triana en Sevilla, son los principales productores de botijas utilizadas en el comercio con Canarias y América desde finales del siglo XV (Amores y Chisvert 1993; Escribano y Mederos e.p.). Así, por ejemplo, la muestra SG 2 (Tabla 4), que corresponde a una botija del tipo A, con cronología entre 1475 y 1800, por su composición mineralógica se asocia con el valle del Guadalquivir, correlacionándose con la Clase 15 o Haltern 70 (Peacock y Williams 1986: 115), fabricadas igualmente en la Bética.

Este caso ejemplifica el problema básico de confirmación por simple correlación petrográfica, y es que tanto un ánfora fabricada en el valle del Guadalquivir como una botija de los siglos XV-XVIII elaborada con arcillas de similar procedencia, pueden presentar similar composición petrográfica. Ello se puede obviar cuando disponemos de la tipología de la pieza, sin embargo, en el caso de El Bebedero carecemos de formas reconstruibles salvo un cuello de ánfora y un posible pivote.

Por ello es importante la serie de dataciones del yacimiento (vide supra) que nos marca una banda cronológica entre $c a .30-50$ D.C. hasta ca.420 D.C., y resulta coherente con las atribuciones temporales anfóricas.

La conexión con cerámicas italianas de época moderna sólo podría plantearse durante el siglo XIV, y particularmente en su primera mitad. Lanzarote deriva su nombre de la presencia en la isla entre 1302-1338 (Serra 1961: 4), 1310-1339 (Caddeo 1928: 52) o 1312-1332 (de la Ronciére 1925; Bonnet 1944: 597; Álvarez Delgado 1954: 11) del genovés Lazzạotto Malocello, quien aparentemente había estado al servicio del rey de Portugal y de su almirante, el genovés Manuel Pessagno. Durante tal periodo, dominará Lanzarote mediante un pacto con los aborígenes de la isla.

Es presumible que durante la etapa de dominación genovesa de la isla arribaran otras expediciones de dicho origen, porque en 1339 el mallorquín Angelino Dulcert dibuja por primera vez en el medievo a las Canarias Orientales, y en Lanzarote figura el escudo genovés, señal de su dominio.

Desde la conquista normanda de la isla entre 1402-1412, en la que Jean de Béthencourt crea un señorío vinculado a Enrique III de Castilla, y especialmente cuando su sobrino Maciot de Béthencourt vende en 1418 sus derechos sobre Lanzarote, Fuerteventura y El Hierro al Conde de Niebla, pasando las islas a la jurisdicción de las Leyes Generales de Castilla, esa relación con Italia se diluye.

Más difícil aún sería buscar una relación con Túnez, aunque las Islas Canarias, y particularmente Lanzarote, fueron objeto de múltiples ataques piráticos de flotillas procedentes de Safí y Larache (Marruecos), Argel y Salé (Argelia) o Túnez durante finales del s. XVI e inicios del s. XVII. Además, si es correcta nuestra propuesta de asignar la Clase 40 a una Benghazi MR 1 implicaría una conexión con la Tripolitania, actual Libia, difícilmente sostenible en época bajomedieval o moderna.

Si tratamos de relacionar la información estratigráfica con las correlaciones propuestas a través del análisis petrográfico y las asociaciones de fragmentos de un mismo recipiente cerámico (Tabla 5), se observa que la cerámica a torno definida como de ánforas romanas sólo aparece entre los estratos superficial y II con un fragmento en el estrato I, y ya más abundantemente a partir del estrato III, que su excavador (P. Atoche, com. pers.) relaciona con el inicio del estrato III, en contacto con el estrato IV, o a alguna posible intrusión.

Más problemático es la definición del contenedor 9 (Tablas 2 y 5), puesto si en el texto (Atoche et alii 1995: 127, 129-130,133) plantean en numerosas ocasiones que se trata posiblemente de un recipiente que incluiría los fragmentos 1,3,10,11,16a y b, 32, el análisis petrográfico de tres fragmentos da características diferenciales para cada uno de ellos. La muestra LA 11, presenta un $60 \%$ de micaesquistos, $25 \%$ de rocas graníticas, $5 \%$ de cuarzo y $4 \%$ de rocas calcáreas. La muestra LA 16 mantiene el $60 \%$ de micaesquistos, pero varía en el $25 \%$ de cuarcitas, $6 \%$ de cuarzo y $5 \%$ de rocas calcáreas. Más claramente se distancia la muestra LA 32, por cuanto su composición es el 30\% de micaesquistos, $30 \%$ de cuarzo, $25 \%$ de rocas cuarcíticas y $10 \%$ de pizarra, propugnándose además un origen más concreto, del triplete 
Sierra Morena-Guadalquivir-Sistema Bético citado para LA 11 y 16, a ceñirlo sólo a Guadalquivir en el caso de LA 32. E incluso se presupone diferente correlación anfórica en base al análisis petrográfico, frente a las Clases 26/Dressel 23, 25/Dressel 20 y 23/Almagro 51C asignadas a LA 11 y 16 se opta para la muestra LA 32, las clases 20/Dressel 14 y 25/Dressel 20 para LA 32.

\begin{tabular}{|c|c|c|c|c|c|}
\hline Muestra & Estrato & Grupo & $\begin{array}{l}\text { Composición } \\
\text { mineralógica }\end{array}$ & Procedencia & $\begin{array}{l}\text { Cronología o tipo de } \\
\text { ánfora asignada }\end{array}$ \\
\hline $\begin{array}{l}\text { LA } 18 \text {, vidriado } \\
\text { melado interior }\end{array}$ & I & 4 & $\begin{array}{l}\text { cuarzo, feldespato } \\
\text { potásico micaesquistos, } \\
\text { pizarras }\end{array}$ & Sur Península Ibérica & musulmana \\
\hline LA 13 & IV & 7 & $\begin{array}{l}\text { cuarzo, calcáreas, lutí- } \\
\text { tas ferruginosa, feldes- } \\
\text { pato potásico (ortosa) }\end{array}$ & $?$ & $?$ \\
\hline LA 4 & IV & 6 & $\begin{array}{c}\text { cuarzo, calcáreas, } \\
\text { fósiles }\end{array}$ & $?$ & ¿romano? \\
\hline LA 9 & IV & 6 & $\begin{array}{l}\text { cuarzo, calcáreas, } \\
\text { fósiles }\end{array}$ & $?$ & ¿romano? \\
\hline SG 1 & $\begin{array}{l}\text { Islote del } \\
\text { Amor }\end{array}$ & 10 & $\begin{array}{l}\text { cuarzo, calcáreas, } \\
\text { micaesquistos }\end{array}$ & Guadalquivir & $\begin{array}{c}\text { S. XVII-XVIII } \\
\text { Clase 15/Haltern 70 } \\
\text { Clase 25/Dressel } 20\end{array}$ \\
\hline SG 2 & $\begin{array}{l}\text { Islote del } \\
\text { Amor }\end{array}$ & 10 & $\begin{array}{l}\text { cuarzo, calcáreas, } \\
\text { micaesquistos }\end{array}$ & Guadalquivir & $\begin{array}{c}\text { S. XVII-XVIII } \\
\text { Clase } 15 / \text { Haltern } 70\end{array}$ \\
\hline SG 3 & $\begin{array}{l}\text { Islote del } \\
\text { Amor }\end{array}$ & 11 & cuarzo, calcáreas & $?$ & S. XVII-XVIII \\
\hline LG 94 & $\begin{array}{c}\text { Museo } \\
\text { Tirajana }\end{array}$ & & $\begin{array}{l}\text { cuarzo, ortosa, volcáni- } \\
\text { cas (latita-traquita) }\end{array}$ & ? & Beltrán 74 \\
\hline
\end{tabular}

Tabla 4. Producciones de cronología histórica o indeterminada de El Bebedero (LA=Lanzarote), islote de la Graciosa (LG=La Graciosa) e Islote del Amor (junto a Arrecife) analizadas en Atoche et alii (1995: 61-71, 114-118, 122-126). SG= Museo de San Gabriel. Las diferencias de la muestra SG 3 con SG 1 y 2 deriva de que no se trata de una botija, tal como parece intuirse por la fotografía, pese a la opinión favorable de Atoche et alii (1995: 68-69, lám. 12/1).

Este ejemplo demuestra que hubiera sido deseable una analítica de todos los fragmentos cerámicos a torno, a pesar de su coste, porque las asignaciones exclusivamente visuales, mediante descripción de su pasta, pueden inducir a agrupaciones en contenedores incorrectas. Un análisis del fragmento 19 podría despejar las dudas sobre la única pieza romana en el estrato I, respecto a que si realmente se corresponde con los fragmentos 2 y 14, asignables a la Benghazi MR 1 .

En suma, la cuestión básica es que sería deseable disponer en el futuro de información adicional que complemente a la obtenida por los análisis petrográficos, ratificados por los análisis de $\mathrm{C}^{14}$, eliminando así cierto grado de incertidumbre al desconocerse tanto las formas de los fragmentos amorfos a torno como por la ausencia de cerámicas romanas muy características, caso de la Terra sigillata, que tienen su punto más meridional de distribución en Mogador. 


\begin{tabular}{|c|c|c|c|c|c|}
\hline ESTRATOS & I & II & III & IV & $\mathbf{V}$ \\
\hline POTENCIA & 0.27 & $0.11-0.16$ & $0.19-0.24$ & $0.45-0.53$ & 0.35 \\
\hline $\mathbf{N}^{\circ}$ FRAGMENTOS & 3 & 1 & 17 & 47 & 1 \\
\hline CONTENEDOR 2 & musulmán & musulmán & musulmán & & \\
\hline CONTENEDOR 3 & Benghazi MR & & & Benghazi MR 1 & \\
\hline CONTENEDOR 4 & & & Dressel 1 & & \\
\hline CONTENEDOR 9 & & & $2(1,16 \mathbf{a})$ & $5(3,10, \mathbf{1 1}, 16 \mathbf{b}, 32)$ & \\
\hline CONTENEDOR 9A (11) & & & & Dressel 23 & \\
\hline CONTENEDOR 9B (16) & & & Dressel 23 & Dressel 23 & \\
\hline CONTENEDOR 9C (32) & & & & Dressel 14 o 20 & \\
\hline CONTENEDOR 10 & & & Dressel 1 & Dressel 1 & \\
\hline CONTENEDOR 15 & & & & Dressel 1 & Dressel \\
\hline
\end{tabular}

Tabla 5. Correlación estratigráfica entre la distribución de los fragmentos cerámicos a torno con sus correspondientes asignaciones anfóricas tras el análisis petrográfico. Se resaltan en negrilla los fragmentos del contenedor cerámico 9 objeto de análisis petrográfico, que dividimos en los contenedores cerámicos $9 \mathrm{~A}-\mathrm{C}$.

Estas cerámicas romanas de El Bebedero no supondrían las primeras documentadas en las Islas Canarias, como demuestran los hallazgos subacuáticos desde 1964, pero sí serían los primeros indicios de cerámica romana a torno en un yacimiento terrestre canario, aunque no en un contexto doméstico de habitación, lo que exige aplicar en el futuro modelos sobre algún tipo de proceso de aculturación, por muy escasa que sea aún esta muestra de 70 fragmentos cerámicos a torno.

\section{LA ATRIBUCIÓN ROMANA DE LAS ÁNFORAS DE YACIMIENTOS SUBACUÁTICOS CANARIOS}

Un serio punto de discrepancia es que Atoche et alii (1995: 68, 70-71, lám. 13/1, 76, 126) y Beltrán Lloris (1995: 9) consideran errónea la atribución romana de las dos ánforas K-109, procedentes del islote de La Graciosa (fig. 2), actualmente depositadas en el Museo Canario y Museo Arqueológico de La Fortaleza de Santa Lucía de Tirajana, propugnando una procedencia del Mediterráneo Central y cronología renacentista del siglo XVI, entre el 1500-1580, tras clasificarlas como tipo 1 de Goggin.

Estas marcadas suspicacias o rechazo sobre una atribución romana de las K-109/Beltrán 74 sigue una línea sostenida cada vez por más autores canarios desde principios de los ochenta (Tejera, sólo inicialmente, en García 1980: 3; Arnay et alii 1983: 627; Martín de Guzmán 1986: 29; de León y Robayna 1989: 39; Herrera 1990: 84; Delgado 1990: 40), a la cual sólo los firmantes se han opuesto (Escribano y Mederos 1996a: 76-77, 85 y 1996b: 45) ampliando simultáneamente la serie de ánforas romanas procedentes del litoral canario.

Además, el rechazo a su atribución romana supone romper con la unanimidad que los especialistas en cerámica romana habían sostenido para estas ánforas en la década de los sesenta y setenta (García y Bellido 1967: 375; Beltrán Lloris 1970: 576, fig. 237/2; Pellicer 1970: 47), incluso incluyéndolas concretamente en la variante Ágora K 109 (Serra 1966: 375; Parker 1992: 96), si ahora nos atenemos a 
las nuevas opiniones contrarias de Paz Peralta (en Atoche et alii 1995: 71, 76) y Beltrán Lloris (1995: 9), quien revisa su opinión precedente.

Esta visión negativa es importante porque todos los trabajos de los sesenta sólo disponían de dos ánforas casi completas del tipo K-109 y un cuello de ánfora de una Almagro 51C procedente del S.E. de Lanzarote (fig. 2). Sobre esta última, aunque Atoche et alii (1995: 76) reconocen que las "características de su perfil, borde, asas, cuerpo y tamaño la diferencian claramente de los tipos de los siglos XVI-XIX", mantienen que las atribuciones romanas al tipo Almagro 51C son simplemente "supuestas".

Sin embargo, es interesante señalar que si se rechaza la atribución romana de las ánforas aparecidas en yacimientos subacuáticos, curiosamente entonces las cerámicas a torno procedentes de El Bebedero serían las primeras y únicas "auténticamente" romanas encontradas en las Islas Canarias.

En este sentido hay verdadero interés en enfatizar (Ib. 1995: 12, 76, 105) "que los primeros testimonios de elementos materiales de la cultura romana en las Islas Canarias han sido identificados en el yacimiento de El Bebedero" (Ib. 1995: 76), y consecuentemente, "constituyen los primeros objetos localizados en Canarias de comprobada adscripción cultural romana, ya que los elementos cerámicos localizados hasta la actualidad en aguas de Lanzarote y considerados romanos se han mostrado claramente más tardíos (siglos XVI-XIX)" (Ib. 1995: 12).

Lo más sorprendente de esta propuesta es que el argumento principal que sostiene el rechazo de esta asignación (Ib. 1995: 68,71) es su ausencia en la serie de análisis petrográficos de Peacock y Williams (1985) y entre los aún inéditos efectuados de ánforas de la Casa de los Delfines de la Colonia Celsa (Zaragoza). Sin embargo, cuando tienen el mismo problema con una Almagro 51C del pecio Cabrera III, priorizan el argumento tipológico (Atoche et alii 1995: 60) (vide supra). A nivel formal también destacan la unión imperfecta de las asas al cuerpo y la estrechez de la boca de la K-109 (Ib. 1995: 71).

Frente a esta opinión, es importante resaltar que los componentes volcánicos que caracterizan la lámina delgada (LG 94) realizada del ánfora depositada en el Museo de San Bartolomé de Tirajana (Tabla 6), coinciden con la procedencia que sostenemos para las K-109, el Mar Egeo, puesto que en dicha región existen rocas volcánicas en las Cícladas (Melos, Kimolos, Poliagos, Tera), Psara, Lesbos, Ayios Efstratios, Limnos, Samotracia, Eubea, Beocia, Egina y en áreas puntuales de la Argolide y Laconia. Detalles técnicos como la estrechez de su cuello derivan de su presumible empleo para transportar vino.

En trabajos precedentes ya hemos desarrollado in extenso el análisis de las ánforas romanas procedentes de yacimientos subacuáticos en las Islas Canarias, inicialmente restringidas a las islas de La Graciosa, Lanzarote y Tenerife (Escribano y Mederos 1996a: 81-85), y posteriormente ampliadas a Fuerteventura y Gran Canaria (Ib. 1996b: 45-46), por lo que sintetizamos la información sobre las mismas (Tabla 6).

A pesar de estas dos posibles correlaciones entre las muestras de El Bebedero con la cerámica romana de hallazgos submarinos en Canarias (Tabla 6), los tipos cerámicos por los que parecen optar Atoche et alii (1995: 55 nota 28,71-72, fig. 6) son la Dressel 1/Clases 3-5 (Campania), Dressel 23/Clase 26 (Bética) y Africana I-II/Clases 33-34 (Túnez). 


\begin{tabular}{|c|c|c|c|c|c|}
\hline Procedencia & Tipo & Lugar fabricación & $\begin{array}{l}\text { Contenido } \\
\text { probable }\end{array}$ & $\begin{array}{l}\text { Cronología } \\
\text { máxima }\end{array}$ & $\begin{array}{c}\text { Correlación } \\
\text { muestras } \\
\text { Bebedero }\end{array}$ \\
\hline $\begin{array}{c}\text { La Graciosa } \\
(3 \text { conservadas })\end{array}$ & $\begin{array}{c}\text { Agora K-109 } \\
\text { Beltrán } 74 \\
\text { A-ORI Rb } 109\end{array}$ & Mar Egeo & ¿Vino? & 200-400 d.C. & $\begin{array}{c}\text { LG } 94 \\
\text { hallazgo } \\
\text { subacuático }\end{array}$ \\
\hline S.E. Lanzarote & $\begin{array}{c}\text { Almagro 51C } \\
\text { Keay XXIII } \\
\text { Class } 23 \\
\text { A-LUS A51C }\end{array}$ & Lusitania. Portugal & $\begin{array}{l}\text { Salmueras } \\
\text { ¿garum? }\end{array}$ & $100-450$ d.C. & ¿LA 11 y $18 ?$ \\
\hline S.E. Tenerife & Dressel 2-4 & Lacio o Campania & Vino & $\begin{array}{l}125 \text { a.C.- } \\
150 \text { d.C. }\end{array}$ & - \\
\hline $\begin{array}{l}\text { S.E. La Graciosa- } \\
\text { N. Lanzarote }\end{array}$ & $\begin{array}{l}\text { Dressel 7-11 } \\
\text { Beltrán 1 }\end{array}$ & Bética. Andalucía & $\begin{array}{l}\text { Salazones } \\
\text { ¿Salmue- } \\
\text { ras? }\end{array}$ & $\begin{array}{l}25 \text { a.C.- } \\
150 \text { d.C. }\end{array}$ & - \\
\hline S.E. Tenerife & $\begin{array}{c}\text { Benghazi MR amp- } \\
\text { hora } 1 \\
\text { Agora M } 254 \\
\text { Bẹltrán } 76 \\
\text { Class } 40\end{array}$ & $\begin{array}{c}\text { ¿Tripolitania?. } \\
\text { Libia }\end{array}$ & ¿Vino? & $1-400$ d.C. & $\begin{array}{l}\text { LA } 2 \\
\text { LA } 14\end{array}$ \\
\hline N.W. Tenerife & $\begin{array}{c}\text { Africana II } \\
\text { Africana IIA Grande } \\
\text { Beltrán II } \\
\text { Keay IV o VII } \\
\text { Class } 34\end{array}$ & $\begin{array}{l}\text { Byzacene. } \\
\text { Túnez }\end{array}$ & $\begin{array}{c}\text { Aceite } \\
\text { Salazones }\end{array}$ & 175-500 d.C. & - \\
\hline S. Gran Canaria & $\begin{array}{l}\text { ¿Pascual 1? } \\
\text { ¿Dressel 1? } \\
\text { ¿Class 6? }\end{array}$ & $\begin{array}{l}\text { Tarraconense. } \\
\text { Cataluña }\end{array}$ & vino & $\begin{array}{l}50 \text { a.C.- } \\
50 \text { d.C. }\end{array}$ & - \\
\hline Fuerteventura & $\begin{array}{c}\text { Dressel } 30 \\
\text { Ostia V } \\
\text { Keay IB2 } \\
\text { Class } 38\end{array}$ & $\begin{array}{l}\text { Mauritania Cesarienne. } \\
\text { Norte de Argelia }\end{array}$ & vino & $150-400$ d.C. & - \\
\hline
\end{tabular}

Tabla 6. Ánforas encontradas en yacimientos subacuáticos de las Islas Canarias. Fuentes: Escribano y Mederos (1996a: 81-85 y 1996b: 45-46).

\section{TIEMPOS SIMULTÁNEOS: MOGADOR-CANARIAS}

Respecto a las ánforas procedentes de yacimientos subacuáticos canarios, el límite más antiguo de la Dressel 2-4 recientemente se fecha en el 30 a.C. (Raynaud 1993b: 56) o el 25 a.C. por Peacock y Williams (1985: 106), frente a la clásica propuesta de Beltrán Lloris (1970: fig. 240) que alcanzaba el 125 a.C.

El límite más reciente del 500 D.C. para la Africana II es defendido exclusivamente por Peacock y Williams (1985: 156-157), mientras la sistematización más reciente la restringe al 280 D.C. (Raynaud y Bonifay 1993:16), Beltrán Lloris (1970: fig. 240) apunta un 375 D.C., y finalmente Sciallano y Sibella (1991: 81) optan por el 425 D.C. 
A la vista de estos datos, un dato que merece enfatizarse por su importancia es que la cronología de las ánforas romanas documentadas en yacimientos subacuáticos de las islas e islotes de La Graciosa, Lanzarote, Fuerteventura, Gran Canaria y Tenerife (Escribano y Mederos 1996a y 1996b) resulta completamente coherente con la ocupación romana del islote de Mogador. La banda cronológica marca intervalos homogéneos entre el 50 A.C.-400/450 D.C (Tablas 7 y 8), similar a Mogador niveles 2b-2a, 50 A.C.-470 D.C. (Tabla 9-10).

Los límites de estos niveles $2 b$ y $2 a$ de Mogador vienen caracterizados por la cerámica aretina de barniz negro ca. 50-25 a.C., monedas desde Juba II (18-19 D.C.) hasta Juliano (361-363 D.C.) (Tabla 9) y Terra sigillata africana ca. 320-470 d.C. (Villaverde 1992: 347, 355).

$\begin{array}{lcccccccccccccc}\text { Cronología } & \mathbf{1 5 0} & \mathbf{1 0 0} & \mathbf{5 0} & \mathbf{0} & \mathbf{5 0} & \mathbf{1 0 0} & \mathbf{1 5 0} & \mathbf{2 0 0} & \mathbf{2 5 0} & \mathbf{3 0 0} & \mathbf{3 5 0} & \mathbf{4 0 0} & \mathbf{4 5 0} & \mathbf{5 0 0} \\ \text { Dressel 2-4 } & \mathrm{X} & \mathrm{X} & \mathrm{X} & \mathrm{X} & \mathrm{X} & \mathrm{X} & \mathrm{X} & & & & & & & \\ \text { ¿Pascual 1? } & & & \mathrm{X} & \mathrm{X} & \mathrm{X} & & & & & & & & & \\ \text { Dressel 7-11 } & & & \mathrm{X} & \mathrm{X} & \mathrm{X} & \mathrm{X} & \mathrm{X} & & & & & & & \\ \text { Bengazi MR } & & & & \mathrm{X} & \mathrm{X} & \mathrm{X} & \mathrm{X} & \mathrm{X} & \mathrm{X} & \mathrm{X} & \mathrm{X} & \mathrm{X} & & \\ \text { Almagro 51C } & & & & & \mathrm{X} & \mathrm{X} & \mathrm{X} & \mathrm{X} & \mathrm{X} & \mathrm{X} & \mathrm{X} & \mathrm{X} & \\ \text { Dressel 30 } & & & & & & \mathrm{X} & \mathrm{X} & \mathrm{X} & \mathrm{X} & \mathrm{X} & \mathrm{X} & & \\ \text { Africana II } & & & & & & \mathrm{X} & \mathrm{X} & \mathrm{X} & \mathrm{X} & \mathrm{X} & \mathrm{X} & \mathrm{X} & \mathrm{X} \\ \text { Ágora K-109 } & & & & & & & \mathrm{X} & \mathrm{X} & \mathrm{X} & \mathrm{X} & \mathrm{X} & & \end{array}$

Tabla 7. Distribución de los intervalos máximos atribuidos a las ánforas encontradas en hallazgos subacuáticos de las Islas Canarias por distintos autores. Almagro Basch (1955); Robinson (1959); Beltrán Lloris (1970); Keay (1984); Peacock y Williams (1985); Sciallano y Sibella (1991); Raynaud (1993a, b, c y d) y Raynaud y Bonifay (1993).

$\begin{array}{ccccccccccccccc}\text { Cronología } & 150 & 100 & 50 & \mathbf{0} & \mathbf{5 0} & \mathbf{1 0 0} & \mathbf{1 5 0} & \mathbf{2 0 0} & \mathbf{2 5 0} & \mathbf{3 0 0} & \mathbf{3 5 0} & \mathbf{4 0 0} & \mathbf{4 5 0} & \mathbf{5 0 0} \\ \text { Gran Canaria } & & & \mathrm{X} & \mathrm{X} & \mathrm{X} & & & & & & & & & \\ \text { Tenerife } & \mathrm{X} & \mathrm{X} & \mathrm{X} & \mathrm{X} & \mathrm{X} & \mathrm{X} & \mathrm{X} & \mathrm{X} & \mathrm{X} & \mathrm{X} & \mathrm{X} & \mathrm{X} & \mathrm{X} & \mathrm{X} \\ \text { Lanzarote } & & & \mathrm{X} & \mathrm{X} & \mathrm{X} & \mathrm{X} & \mathrm{X} & \mathrm{X} & \mathrm{X} & \mathrm{X} & \mathrm{X} & \mathrm{X} & \mathrm{X} & \\ \text { Fuerteventura } & & & & & & & \mathrm{X} & \mathrm{X} & \mathrm{X} & \mathrm{X} & \mathrm{X} & \mathrm{X} & & \\ \text { La Graciosa } & & & & & & & & \mathrm{X} & \mathrm{X} & \mathrm{X} & \mathrm{X} & \mathrm{X} & & \end{array}$

Tabla 8. Presencia de cerámica romana en las distintas islas de Canarias en función de los intervalos temporales de las ánforas halladas en ellas. Obsérvese la primacía de Tenerife, quizás también la primera poblada, como actualmente sugieren las dataciones radiocarbónicas disponibles (vide infra, Tabla 11) y el aparente apogeo de estos contactos entre el 150-400 d.C. 


$\begin{array}{ccr}\text { NIVEL } & \text { EMPERADOR o REY } & \text { CRONOLOGÍA } \\ \text { IIB } & \text { Juba II } & 18-19 \\ \text { IIB } & \text { Claudio } & 41-54 \\ \text { IIB } & \text { Domiciano } & 81-96 \\ \text { IIB } & \text { ¿Adriano? } & 117-138 \\ \text { IIA } & \text { Commodo } & 176-192 \\ \text { IIA } & \text { Julia, madre de Alejandro Severo } & 222-235 \\ \text { IIA } & \text { Gordiano III } & 238-244 \\ \text { IIA } & \text { Galieno } & 253-268 \\ \text { IIA } & \text { Claudio II el Gótico } & 268-270 \\ \text { IIA } & \text { Maximino Augusto } & 286-305 \\ \text { IIA } & \text { Constantino I } & 306-337 \\ \text { IIA } & \text { Constantino II (Occidente) } & 337-340 \\ \text { IIA } & \text { Constante I (Occidente) } & 337-350 \\ \text { IIA } & \text { Constancio II (Oriente) } & 337-361 \\ \text { IIA } & \text { Juliano } & 361-363\end{array}$

Tabla 9. Monedas romanas en Mogador. Fuentes: Thouvenot (1954: 465), Desjacques y Koeberlé (1955: 200, 202) y Jodin (1967: 24, 243-252)

$\begin{array}{ccccccc}\text { MOTIVo } & 350 & 375 & \mathbf{4 0 0} & \mathbf{4 2 5} & \mathbf{4 5 0} & \mathbf{4 7 5} \\ \text { Círculo concéntrico } & \mathrm{X} & \mathrm{X} & \mathrm{X} & \mathrm{X} & \mathrm{X} & \\ \text { Círculo concéntrico con orla dentellada } & \mathrm{X} & \mathrm{X} & \mathrm{X} & \mathrm{X} & \mathrm{X} & \mathrm{X} \\ \text { Círculo concéntrico } & \mathrm{X} & \mathrm{X} & \mathrm{X} & \mathrm{X} & \mathrm{X} & \mathrm{X} \\ \text { Círculo seccionado } & \mathrm{X} & \mathrm{X} & \mathrm{X} & \mathrm{X} & \mathrm{X} & \mathrm{X} \\ \text { Círculo concéntrico con orla } & & & \mathrm{X} & \mathrm{X} & & \\ \text { Cuadrado, reticulado } & \mathrm{X} & \mathrm{X} & \mathrm{X} & \mathrm{X} & \mathrm{X} & \mathrm{X} \\ \text { Palma } & \mathrm{X} & \mathrm{X} & & & & \\ \text { Palma } & \mathrm{X} & \mathrm{X} & \mathrm{X} & & & \\ \text { Palma } & \mathrm{X} & \mathrm{X} & \mathrm{X} & \mathrm{X} & & \\ \text { Palma } & \mathrm{X} & \mathrm{X} & \mathrm{X} & \mathrm{X} & \mathrm{X} & \mathrm{X} \\ \text { Palma } & \mathrm{X} & \mathrm{X} & \mathrm{X} & \mathrm{X} & & \\ \text { Palma } & \mathrm{X} & \mathrm{X} & \mathrm{X} & & & \end{array}$

Tabla 10. Cronología d.C. de los motivos decorativos estampados de la vajilla fina de mesa africana de Mogador. Fuente: Villaverde (1992: 355).

No deja de ser igualmente interesante apreciar cómo los intervalos máximos y mínimos calibrados de El Bebedero coinciden con las de los ánforas de yacimientos subacuáticos canarios y las fases $2 \mathrm{~b}-2 \mathrm{a}$ de 
Mogador. En este sentido, la banda cronológica indica un 200 A.C.-500 D.C., y ciñéndola más, entre el 100-400 D.C. (Tabla 11).

$\begin{array}{ccccccccccccc}\text { Cronología } & 350 & \mathbf{3 0 0} & \mathbf{2 0 0} & \mathbf{1 0 0} & \mathbf{0} & \mathbf{1 0 0} & \mathbf{2 0 0} & \mathbf{3 0 0} & \mathbf{4 0 0} & \mathbf{5 0 0} & \mathbf{6 0 0} & \mathbf{6 5 0} \\ \text { Bebedero IV } & \mathrm{X} & \mathrm{X} & \mathrm{X} & \mathrm{X} & \mathbf{X X} & \mathrm{X} & \mathrm{X} & \mathrm{X} & \mathrm{X} & & & \\ \text { Bebedero IV } & & & \mathrm{X} & \mathrm{X} & \mathrm{X} & \mathbf{X X} & \mathrm{X} & \mathrm{X} & \mathrm{X} & \mathrm{X} & & \\ \text { Bebedero IV-V } & & & & \mathrm{X} & \mathrm{X} & \mathbf{X X} & \mathrm{X} & \mathrm{X} & & & & \\ \text { Bebedero IV base } & & & & & \mathrm{X} & \mathrm{X} & \mathbf{X X} & \mathrm{X} & \mathrm{X} & & & \\ \text { Bebedero III-IV } & & & & & & & \mathrm{X} & \mathrm{X} & \mathbf{X X} & \mathrm{X} & \mathrm{X} & \mathrm{X}\end{array}$

Tabla 11. Distribución de los intervalos máximo y mínimos de las determinaciones radiocarbónicas de El Bebedero. Las fechas más probables se enfatizan con dos XX.

Esta homogeneidad temporal entre Mogador y Canarias no creemos que pueda deberse a factores accidentales y pone en evidencia la íntima relación que tuvo Mogador en la ruta hacia el Sur que tuvo su límite meridional en las Islas Canarias (fig. 3). Una importante motivación habría que buscarla en el mantenimiento del interés por los caladeros pesqueros norteafricanos, tal como demuestran las factorías de salazón de Lixus entre los siglos I y $\mathrm{V}$ d.C., que parece ser la única actividad económica que mantiene un relativo dinamismo a partir del siglo IV d.C. (Tabla 11).

$\begin{array}{lccccccccccc}\text { Cronología } & 100 & \mathbf{0} & \mathbf{1 0 0} & \mathbf{2 0 0} & \mathbf{3 0 0} & \mathbf{4 0 0} & \mathbf{5 0 0} & \mathbf{5 2 5} & \mathbf{5 5 0} & \mathbf{5 7 5} & \mathbf{6 0 0} \\ \text { Factoría 1 } & \mathrm{X} & \mathrm{X} & \mathrm{X} & \mathrm{X} & \mathrm{X} & \mathrm{X} & \mathrm{X} & \mathrm{X} & & & \\ \text { Factoría 2 } & & \mathrm{X} & \mathrm{X} & \mathrm{X} & \mathrm{X} & \mathrm{X} & & & & & \\ \text { Factoría 3 } & & \mathrm{X} & \mathrm{X} & \mathrm{X} & \mathrm{X} & \mathrm{X} & \mathrm{X} & & & & \\ \text { Factoría 4 } & & \mathrm{X} & \mathrm{X} & \mathrm{X} & \mathrm{X} & \mathrm{X} & \mathrm{X} & \mathrm{X} & \mathrm{X} & & \\ \text { Factoría 5 } & & \mathrm{X} & \mathrm{X} & \mathrm{X} & & \mathrm{X} & \mathrm{X} & \mathrm{X} & & & \\ \text { Factoría 6 } & & \mathrm{X} & \mathrm{X} & \mathrm{X} & \mathrm{X} & \mathrm{X} & \mathrm{X} & \mathrm{X} & & & \\ \text { Factoría 7 } & & \mathrm{X} & \mathrm{X} & \mathrm{X} & \mathrm{X} & \mathrm{X} & \mathrm{X} & \mathrm{X} & & & \\ \text { Factoría 9 } & & \mathrm{X} & \mathrm{X} & \mathrm{X} & \mathrm{X} & \mathrm{X} & \mathrm{X} & \mathrm{X} & \mathrm{X} & \mathrm{X} & \mathrm{X}\end{array}$

Tabla 12. Cronología de las factorías de salazones y garum de Lixus. Fuentes: Ponsich y Tarradell (1965: 9-37), Ponsich (1988: 103-135) y Villaverde (1992: 346).

\section{CONCLUSIONES}

A la hora de buscar interpretaciones que justifiquen la presencia de ánforas romanas en aguas costeras de las Islas Canarias, que parecen ratificarse con hallazgos terrestres, cinco alternativas explicativas podrían ser esgrimidas, si bien no tendrían que ser necesariamente excluyentes, o podría darse la asociación de dos o más variables.

1) El argumento más simple sería la presencia de naves romanas, que durante trayectos exploratorios a lo largo de la costa atlántica norteafricana realizarían aguadas (Serra 1963-64: 232-233) para proveerse de agua dulce y alimentos frescos, algunas de las cuales pudieron naufragar ocasionalmente. Esta hipótesis 
sobre las aguadas, al ser una primera necesidad de toda embarcación, y más aún en la Antigüedad, resulta complementaría de todas las restantes variables.

2) Una segunda alternativa sería que se realizasen ofrendas en forma de libaciones vertiendo vino por la borda y pronunciando la formula religiosa prescrita, una vez se divisaba un hierón akrotérion o promunturium sacrum, tras la cual se produciría el rompimiento del ánfora (Wachsmuth 1967: 407; Fernández Nieto 1992: 141-142; Delgado Delgado, en preparación). Ello podría explicar la presencia esporádica y fortuita de algunas ánforas vinarias en puntos dispersos del litoral canario, a veces relacionadas con puntas como Guadamojete y Teno, siendo particularmente importante esta última localización en Tenerife.

Sin embargo, no hay una confirmación arqueológica. En algunos casos, el estado de conservación del ánfora es bastante completo o sin fracturas, caso de la posible Pascual 1 de Gran Canaria (Escribano y Mederos 1996b: 46) y las tres de La Graciosa (Ib. 1996a: 81-84), curiosamente las cuatro contenedoras de vino, o las 5 desaparecidas de Lanzarote (Álvarez Delgado 1967: 199). Hay otras ánforas que no transportaban vino sino salmueras, como una Almagro 51C, salazones caso de la Dressel 7-11, o aceite-salazones, la Africana II, que además es la procedente de la punta de Teno. Y si se aceptan los análisis de El Bebedero, la presencia de ánforas en poblados del interior de Lanzarote, las clases 3-5 o Dressel 1A-C, indican ánforas vinarias y la clase 40, o Benghazi MR 1, quizás también fuese vinaria, lo que implicaría que serían aparentemente intercambiadas con la población aborigen. No obstante, esta actividad ritual puede ser también complementaria con otras hipótesis vinculadas a diferentes actividades de estos marinos gaditanos o romanos, caso de aguadas y comercio.

3) Una tercera posibilidad sería asociarlas al proceso de poblamiento del Archipiélago que habría instalado en algunas de ellas un pequeño número de colonos (Álvarez Delgado 1977: 51) o incluso deportado poblaciones contra su voluntad (Abreu y Galindo 1977: 30-31), presumiblemente procedentes del litoral atlántico norteafricano. Esporádicamente, dichos asentamientos serían visitados por algunas embarcaciones romanas. La amplitud cronológica que abarcan las ánforas, desde el siglos I a.C. hasta el IV d.C., sería indicativa de sucesivas visitas, tal vez repoblando ocasionalmente algún asentamiento a lo largo de dicho periodo temporal, en caso de fracasar en alguna isla.

No obstante, si nos atenemos a las determinaciones radiocarbónicas disponibles (Tabla 13), en algunas de las islas como Tenerife y quizás Gran Canaria, ya existiría poblamiento previo, y el propio texto de Plinio el Viejo (N.H. VI202-205) señala la presencia de edificaciones en la isla de Canaria, hacia ca. 25 d.C., aunque incluso la identificación Canaria=Gran Canaria debe tomarse con prudencia y no debe descartarse en última instancia que pudiera referirse a otra isla del archipiélago.

4) Una cuarta alternativa sería asociarlas a la realización de razzias esclavistas en las Islas Canarias. Sin embargo, al incluir etapas temporales como el siglo I d.C., que constituyen fases de expansión fronteriza del Imperio romano, el contingente de prisioneros que entraba dentro de sus fronteras era lo suficientemente importante como para no tener que venir a las Canarias a la búsqueda de los mismos.

A nivel general, la propia existencia de nutridas redes organizadas de trafico esclavistas a lo largo del Imperio, y la ausencia de referencias epigráficas sobre la existencia de esclavos canarios, son dos serios argumentos negativos que inducen a rechazar esta posibilidad. Sin embargo, no puede descartarse que a veces se hubiese capturado a algunos indígenas durante la realización de aguadas. 


\begin{tabular}{|c|c|c|c|c|c|c|c|c|}
\hline Yacimiento & Muncipio-Isla & B.P. & \pm & a.C.-d.C. & $\begin{array}{l}\text { máx. } \\
\text { CAL }\end{array}$ & $\begin{array}{c}\text { CAL } \\
\text { AC-DC }\end{array}$ & $\min$. & $\begin{array}{c}n^{0} \text { y tipo } \\
\text { de } \\
\text { muestra }\end{array}$ \\
\hline $\begin{array}{c}\text { Cueva del Barranco } \\
\text { de la Arena. } \\
\text { Nivel IV-IIIb }\end{array}$ & Candelaria, Tenerife & 2490 & 60 & 540 a.C. & $799 \mathrm{AC}$ & $\begin{array}{c}760 \mathrm{AC} \\
680650 \\
550\end{array}$ & $401 \mathrm{AC}$ & $\begin{array}{l}\text { CSIC- } \\
189 / C\end{array}$ \\
\hline $\begin{array}{c}\text { Cueva del Bco. } \\
\text { de la Arena. } \\
\text { Nivel IIIb-IIIa }\end{array}$ & Candelaria, Tenerife & 1970 & 60 & 20 a.C. & $91 \mathrm{AC}$ & $60 \mathrm{DC}$ & $205 \mathrm{DC}$ & $\begin{array}{l}\text { CSIC- } \\
188 / C\end{array}$ \\
\hline $\begin{array}{l}\text { Cueva de los Guan- } \\
\text { ches. XI. Interior }\end{array}$ & Icod, Tenerife & 2400 & 80 & 450 a.C. & $785 \mathrm{AC}$ & $410 \mathrm{AC}$ & $256 \mathrm{AC}$ & $\begin{array}{l}\text { GaK- } \\
\text { ?/CNZ- } \\
\text { SED }\end{array}$ \\
\hline $\begin{array}{l}\text { Cueva de las Palo- } \\
\text { mas. Nivel VI }\end{array}$ & Icod, Tenerife & 2200 & 90 & 250 a.C. & $403 \mathrm{AC}$ & $\begin{array}{l}340 \mathrm{AC} \\
320 \\
200\end{array}$ & $1 \mathrm{DC}$ & GaK-?/C \\
\hline $\begin{array}{l}\text { Cueva de las Palo- } \\
\text { mas. Nivel IV }\end{array}$ & Icod, Tenerife & 2040 & 100 & 90 a.C. & $361 \mathrm{AC}$ & $40 \mathrm{AC}$ & $216 \mathrm{DC}$ & $\begin{array}{l}\text { GaK- } \\
\text { ?/CNZ- } \\
\text { SED }\end{array}$ \\
\hline $\begin{array}{c}\text { Los Caserones, } \\
\text { Casa } 3\end{array}$ & $\begin{array}{l}\text { La Aldea de San } \\
\text { Nicolás, Gran Canaria }\end{array}$ & 1890 & 150 & 60 d.C. & $198 \mathrm{AC}$ & $120 \mathrm{DC}$ & $446 \mathrm{DC}$ & $\begin{array}{l}\text { GaK- } \\
8064 / \mathrm{M}\end{array}$ \\
\hline
\end{tabular}

Tabla 13. Dataciones más antiguas de las Islas Canarias. $C=$ Carbón. $M=$ Madera. $C N Z=C e n i z a s . ~ S E D=S e d i m e n t o s$. Sólo Tenerife cuenta con determinaciones radiocarbónicas anteriores a la Era. Además las fechas más antiguas de Tenerife del 760-550 AC y 410 AC presentan contextos problemáticos, en la primera, el nivel 4 que carece de ocupación humana y en la segunda, se desconoce aún el contexto arqueológico.

5) La quinta posibilidad estaría en la presencia de algún tipo de factoría en las Islas Canarias, procesando salazones de pescado, que algunos autores defienden desde época púnica (Balbín et alii 1995: 7, 15, 20; González Antón et alii 1995: 14, 24,26), simultáneamente a la realización de capturas de túnidos en las aguas circundantes (García y Bellido 1942: 178 1952: 382 y 1953: 218, 224, 484; Blázquez 1977: 43; Castro 1983: 36; Herrera Piqué 1986: 22; Díaz Alayón y Tejera en Álvarez Rixo 1991: 121; Delgado 1993-95: 72-73; Mederos y Escribano e.p.; Atoche et alii 1995: 110-111). Ello sería posible especialmente en alguna de las dos islas más orientales, Lanzarote y Fuerteventura, que poseen las mejores salinas naturales, las cuales en momentos previos a la conquista castellana aún estaban escasamente pobladas.

Sin embargo, las evidencias arqueológicas disponibles de yacimientos terrestres en dichas islas no han aportado datos positivos sobre la presencia de factorías de salazones.

6) Finalmente, la sexta alternativa sería la existencia de algún tipo de intercambios comerciales, significativa posibilidad a tener en cuenta por el tipo de ánforas documentadas, destinadas a transportar vino, aceite, salmueras y quizás salazones (Escribano y Mederos 1996a: 86-87 y 1996b: 46-47). El producto que por razones históricas siempre ha sido más demandado para intercambiarlo es un producto tintóreo, la orchilla (Roccella sp.), monopolio real hasta 1814 (Tabla 14), del que se obtienen colores rojos, que se intensifican añadiendo ácido acético (vinagre), morados, rosas y violetas, más intensos con sosa cáustica (hidróxido sódico, $\mathrm{NaOH}$ ), que se obtiene por electrólisis de la sal común (cloruro sódico, $\mathrm{NaCl}$ ). 
ISLAS

EL HIERRO
TENERIFE
GRAN CANARIA
LANZAROTE
FUERTEVENTURA
LA GOMERA

PRODUCCIÓN ANUAL EN KGS.

36.800

23.000

18.400

13.800

13.800

13.800

sin datos

Tabla 14. Producción de orchilla en las Islas Canarias hacia 1800. Fuente: Viera y Clavijo (1799-1810/1982: 315). Las islas de El Hierro y La Gomera cuentan con los mejores ejemplares y los de mayores dimensiones (Stone, 1887/1995/2: 324).

En este sentido, creemos que el interés de los navegantes romanos por las islas sugiere una combinación de variables explicativas, y aparte de la necesidad de realizar aguada o continuar una tradición previa de pesca realizada por los marineros gaditanos en el litoral atlántico norteafricano, simultáneamente, quizás además pudo incluir un posible interés por la comercialización de la orchilla, Roccella canariensis, un liquen endémico que se da en todas las Islas Canarias utilizado para la obtención de tintes, lo que explicaría un cierto grado de intercambios con las poblaciones aborígenes que habrá que seguir investigando en el futuro.

\section{AGRADECIMIENTOS}

El director de la excavación de El Bebedero, P. Atoche, amablemente nos comentó sus impresiones sobre las valoraciones que ofrecemos del yacimiento.

\section{BIBLIOGRAFÍA}

ABREU, A. de (1632/1977): Historia de la conquista de las siete islas de Canaria, en A. Cioranescu, A. (ed.), Goya Ed. S/C de Tenerife.

ALMAGRO, M. (1955): Las necrópolis de Ampurias. II. Necrópolis romanas y necrópolis indigenas, Diputación Provincial de Barcelona-Instituto "Rodrigo Caro" de Arqueología y Prehistoria del C.S.I.C. Barcelona.

ÁlVAREZ DELGADO, J. (1954): "Toponimia hispánica de Canarias”, Estudios dedicados a Menéndez. Pidal 5. Madrid: 3-38. (1967): "Hallazgos submarinos", Revista de Historia Canaria XXXI n 153: 198-200.

ÁLVAREZ RIXO, J.A. (1991): Lenguaje de los antiguos isleños, en C. Díaz Alayón y A. Tejera (eds.), Ayuntamiento del Puerto de la Cruz-Centro de la Cultura Popular Canaria. La Laguna-Tenerife.

AMORES, F. de y CHISVERT, N. (1993): "Tipología de la cerámica común bajomedieval y moderna sevillana (ss. XV-XVIII): I. La loza quebrada de relleno de bóvedas", Spal 2: 269-325.

ARNAY, M.; GONZÁLEZ REIMERS, E.; GONZÁLEZ PADRÓN, C. y JORGE, J.A. (1983): “Ánforas prehispánicas en Tenerife", Anuario de Estudios Atlánticos 29: 599-634. 
ATOCHE,P.(1993): "Excavaciones arqueológicas en “El Bebedero" (Teguise, Lanzarote). Segunda campaña, 1987", Eres (Arqueología) 4: 7-19.

ATOCHE, P.; PAZ, J.A.; RAMÍREZ, Ma.A. y ORTIZ, Mª.E. (1995): Evidencias arqueológicas del mundo romano en Lanzarote (Islas Canarias), Colección Rubicón 3, Cabildo Insular de Lanzarote. Irún-Arrecife.

ATOCHE, P.; RODRÍGUEZ ARMAS, Mª.D. y RAMÍREZ, Ma .A. (1989): El yacimiento arqueológico de "El Bebedero" (Teguise, Lanzarote). Resultados de la primera campaña de excavaciones, Universidad de La Laguna-Ayuntamiento de Teguise. La Laguna.

BALBÍN, R. de; BUENO, P.; GONZÁLEZ ANTÓN, R. y ARCO, C. del (1995): "Datos sobre la colonización púnica de las Islas Canarias", Eres (Arqueología) 6: 7-28.

BELTRÁN LLORIS, M. (1970): Las ánforas romanas en España, Diputación Provincial de ZaragozaInstitución Fernando el Católico. Zaragoza.

_ (1995): "Prólogo", en ATOCHE, P.; PAZ, J.A.; RAMÍREZ, Mª.A. y ORTIZ, Mª.E. (1995): Evidencias arqueológicas del mundo romano en Lanzarote (Islas Canarias), Colección Rubicón 3, Cabildo Insular de Lanzarote. Irún-Arrecife: 7-9.

BLÁZQUEZ, J.Ma . (1977): "Las Islas Canarias en la Antigüedad”, Anuario de Estudios Atlánticos 23: 35-51. BONNET, B. (1944): "Las expediciones a las Canarias en el siglo XIV”, Revista de Indias 18: 577-610. CADDEO, R. (1928): Le navigazioni atlantiche di Alvise cà da Mosto e Nicoloso da Recco, Alpes, Milano.

CASTRO, D. (1983): Historia de las Islas Canarias. De la prehistoria al descubrimiento, Editora Nacional. Madrid.

FERNÁNDEZ NIETO, F.J. (1992): “Griegos y colonización griega en la Península Ibérica”, en F. Chaves (ed.): Griegos en Occidente. Sevilla: 129-145.

DELGADO, J. (1990): "La actividad arqueológica subacuática en Canarias", Investigaciones Arqueológicas en Canarias 2: 31-45.

DELGADO DELGADO, J.A. (1993-95): “De Floro a Posidonio: las Insulae Fortunatae de Sertorio", Revista de Historia Canaria 177: 61-74.

DESJACQUES, J. y KOERBELE, P. (1955): “Mogador et les iles purpuraires”, Hesperis 42: 199-202.

ESCRIBANO, G. y MEDEROS, A. (1996a): “¿Ánforas romanas en las Islas Canarias? Revisión de un aparente espejismo histórico", Tabona 9: 75-98.

(1996b): "Canarias. Límite meridional en la periferia del Imperio Romano", Revista de Arqueología 184: $42-47$.

— (e.p.): "Botijas en yacimientos arqueológicos subacuáticos de las Islas Canarias. Una fuente complementaria para el análisis del comercio canario-americano", XII Coloquio de Historia CanarioAmericana (Las Palmas, 1996).

GARCÍA, J.L. (1980): "Las "ánforas romanas" son del siglo XVI y llevaban aceitunas a América", Diario de Avisos 16-1-1980: 3.

GARCÍA Y BELLIDO, A. (1942): Fenicios y carthagineses en Occidente, Escuela de Estudios Hebraicos, C.S.I.C. Madrid.

— (1952): "Colonización Púnica", en R. Menéndez Pidal (coord.) Historia de España, Tomo I, España Primitiva, Volumen II, M. Almagro Basch y A. García y Bellido (eds.): La Protohistoria, Espasa Calpe, $5^{a}$ edición 1989. Madrid: 309-492.

_- (1953): La Península Ibérica en los comienzos de su historia. Una invitación al estudio de nuestra Edad Antigua, Instituto Rodrigo Caro, C.S.I.C. Madrid.

- (1967): Las islas atlánticas en el mundo antiguo, Universidad Internacional de Canarias. Las Palmas. GONZÁLEZ ANTÓN, R.; BALBÍN, R. de; BUENO, P. y ARCO, C. del (1995): La piedra zanata, Museo Arqueológico, Cabildo Insular de Tenerife. La Laguna. 
HERRERA, A. (1986): "Las Islas Canarias en la Antiguiedad", Aguayro 167: 19-26.

IDEAPRESS (1993): "Hallazgo arqueológico romano en Lanzarote", Diario de Avisos 23-11-1993: 17. JODIN, A. (1967): Les etablissements du roi Juba II aux iles purpuraires (Mogador), Editions Marocaines et Internationales. Tanger.

KEAY, S.J. (1984): Late Roman Amphorae in the Western Merditerranean. A typology and economic study: the Catalan evidence, B.A.R. I.S. 196. Oxford.

LEÓN, J. de y ROBAYNA, M.A. (1989): "El jable, poblamiento y aprovechamiento en el mundo de los antiguos mahos de Lanzarote y Fuerteventura”, III Jornadas de Estudios sobre Fuerteventura y Lanzarote (Puerto del Rosario, 1987). Madrid-Puerto del Rosario: 11-105.

MARTÍN DE GUZMÁN, C. (1985-86): “Los problemas de la navegación pre y protohistórica en el mar de Canarias y la fachada Atlántico-Sahariana", V Coloquio de Historia Canario-Americana (Las Palmas, 1982), vol. 4. Las Palmas-Madrid: 25-144.

MARTÍN DE GUZMÁN, C. y ONRUBIA, J. (1990): "Excavaciones en el Parque Arqueológico de la Cueva Pintada (Gáldar, Gran Canaria): Avance de las Campañas de 1987 y 1988”, Investigaciones Arqueológicas en Canarias 2: 135-156.

MARTÍN DE GUZMÁN, C.; ONRUBIA, J.; LLAVORI, R. y SÁENZ, J.I. (1992): “Excavaciones en el Parque Arqueológico Cueva Pintada de Gáldar, Gran Canaria. (Avance de las actuaciones de 1989 y 1990)", Investigaciones Arqueológicas en Canarias 3: 153-205.

MARTÍN DE GUZMÁN, C.; ONRUBIA, J. y SÁENZ, J.I. (1994): "Trabajos en el parque arqueológico de la Cueva Pintada de Gáldar, Gran Canaria. Avance de las intervenciones realizadas entre julio de 1990 y diciembre de 1992", Anuario de Estudios Atlánticos 40: 17-115.

MEDEROS, A. y ESCRIBANO, G. (e.p.): "Producciones anfóricas canarias", $I^{\text {er }}$ Congreso Internacional Canario-Africano: Prehistoria-Edad Media (La Laguna, noviembre 1994).

ONRUBIA, J.; RODRÍGUEZ SANTANA, C.G.; SÁENZ, J.I.; GONZÁLEZ MARRERO, Mª del C. y OLMO, S. (e.p.): "Los materiales arqueológicos "históricos" de la Cueva Pintada de Gáldar (Gran Canaria). Una primera aproximación al contexto de las series bajo y post-medievales”, XII Coloquio de Historia Canario-Americana (Las Palmas, 1996).

OSSORIO, F. (1990): "Hallados restos de cerámica romana y árabe en la Cueva Pintada de Gáldar", La Gaceta de Canarias 9-6-1990: 38.

PARKER, A.J. (1992): Ancient Shipwecks of the Mediterranean \& the Roman Provinces, B.A.R. I.S. 580. Oxford.

PEACOCK, D.P.S. y WILLIAMS, D.F. (1985): Amphorae and the Roman economy. An introductory guide, Longman. London.

PELLICER, M. (1970): “Ánforas de importación halladas en Canarias”, Anuario del Instituto de Estudios Canarios 14-15: 43-56.

PONSICH, M. (1988): Aceite de oliva y salazones de pescado. Factores geo-económicos de Bética y Tingitania, Universidad Complutense. Madrid.

PONSICH, M. y TARRADELL, M. (1965): Garum et Industries Antiques de Salaison dans la Méditerranée Occidentale, Bibliothèque de l'École des Hautes Études Hispaniques 36, Presses Universitaires de France. Paris.

RAYNAUD, C. (1993a): "Amphores de Bétique", Lattara 6: 23-27.

— (1993b): "Amphores italiques d'époque impériale”, Lattara 6: 56-57.

- (1993c): “Amphores de Lusitanie", Lattara 6: 58-59.

_ (1993d): "Amphores de Méditerranée orientale", Lattara 6: 69-73.

RAYNAUD, C. y BONIFAY, M. (1993): “Amphores africaines”, Lattara 6: 15-22. 
ROBINSON, H.S. (1959): Pottery of the Roman Period. Chronology, The Athenian Agora V. Princenton. RONCIERE, Ch. de la (1925): La découverte de l'Afrique au Moyen-Age. Le Caire.

SCIALLANO, M. y SIBELLA, P. (1991):Amphores. Comment les identifier?, Edisud. Aix-en-Provence. SERRA RAFOLS, E. (1961): "Lancelotto Malocello en las Islas Canarias", Congresso Internacional de História dos Descobrimentos, vol. III. Lisboa: 1-14.

_ (1963-64): "La primera ánfora romana hallada en Canarias", Revista de Historia Canaria XXIX: 231-233.

- (1966): "Ánfora antigua en Canarias”, IX Congreso Nacional de Arqueología (Valladolid, 1965). Zaragoza: 373-377.

STONE, O.M. (1887): Tenerife and its six satellites or The Canary Islands past and present, Marcus Ward \& Co. London.

(1995): Tenerife y sus seis satélites, Cabildo Insular de Gran Canaria, 2 vols. Valencia-Las Palmas.

THOUVENOT, R. (1954): "Recherches archéologiques a Mogador", Hesperis 41: 463-467.

VIERA Y CLA VIJO, J. de (1982): Diccionario de Historia Natural de las Islas Canarias. Indice alfabético descriptivo de sus tres reinos: animal, vegetal y mineral, M. Alvar (ed.), Mancomunidad de Cabildos de Las Palmas. Madrid-Las Palmas.

VILLAVERDE, N. (1992): “Aportaciones a la cronología de la antigüedad tardía en Mauritania Tíngitana: datos de las vajillas africanas", Lixus (Larache, 1989), Collection Ecole Francaise de Rome 166. Rome: 337-364.

WACHSMUTH, D. (1967): Pompimos o Daimon. Untersuchung zu den antiken Sakralhandlungen bei Seereisen. Berlin. 


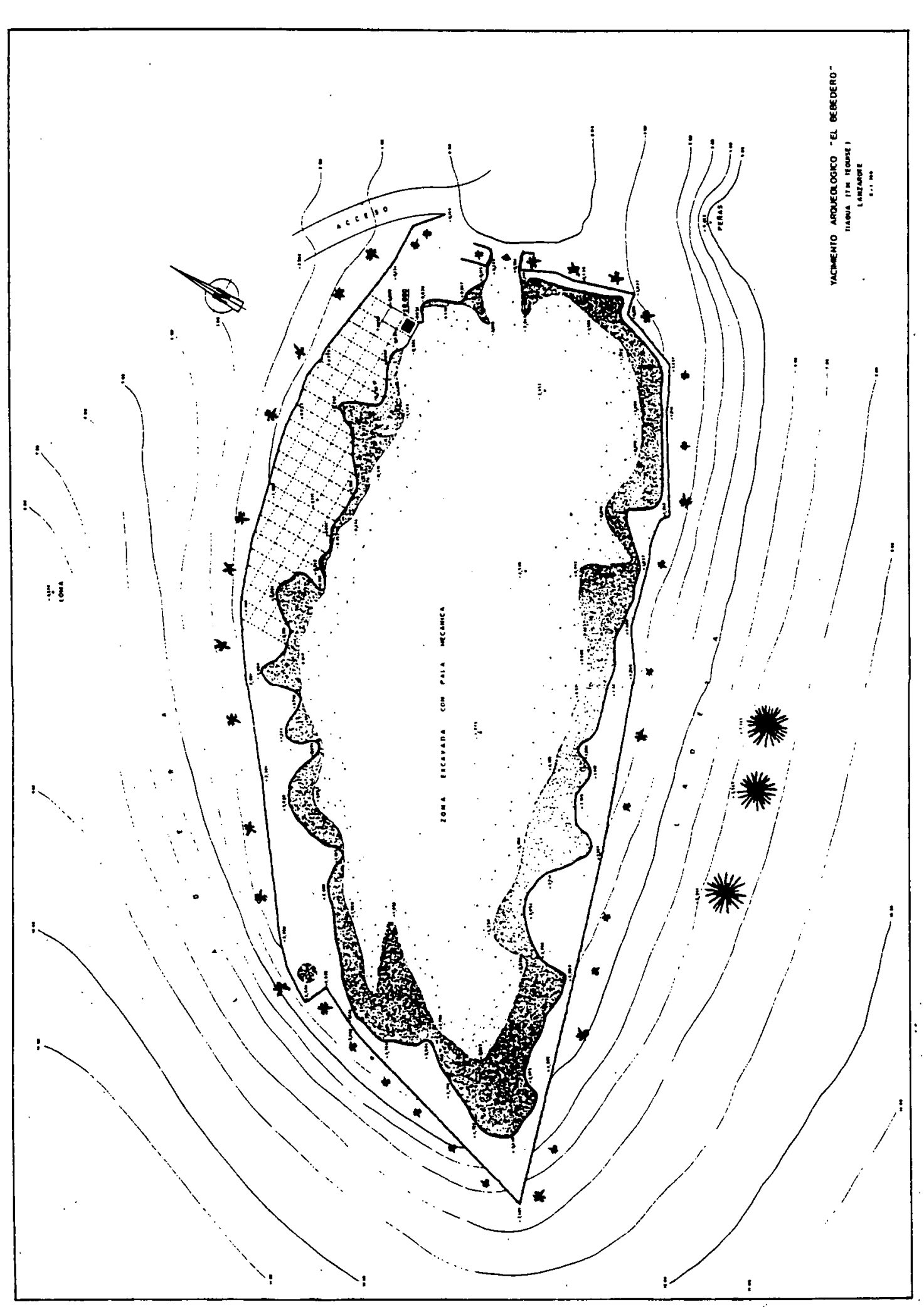




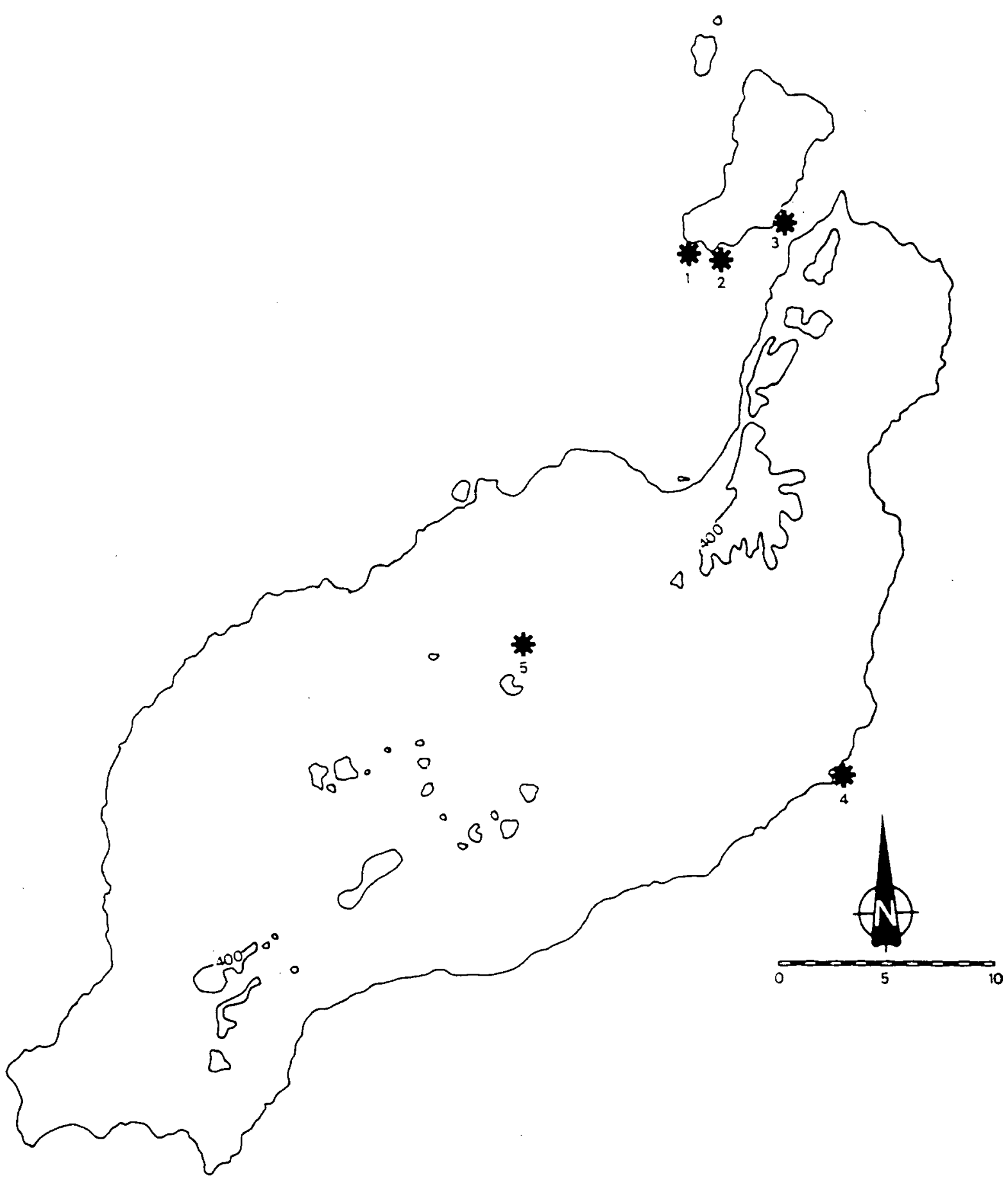

Fig. 2. Yacimientos con presencia de cerámica romana en el islote de La Graciosa e isla de Lanzarote (Canarias Orientales). 1: Playa de La Cocina. 2: Rincón del Salado. 3: El Río. 4: Los Charcos. 5: El Bebedero. 


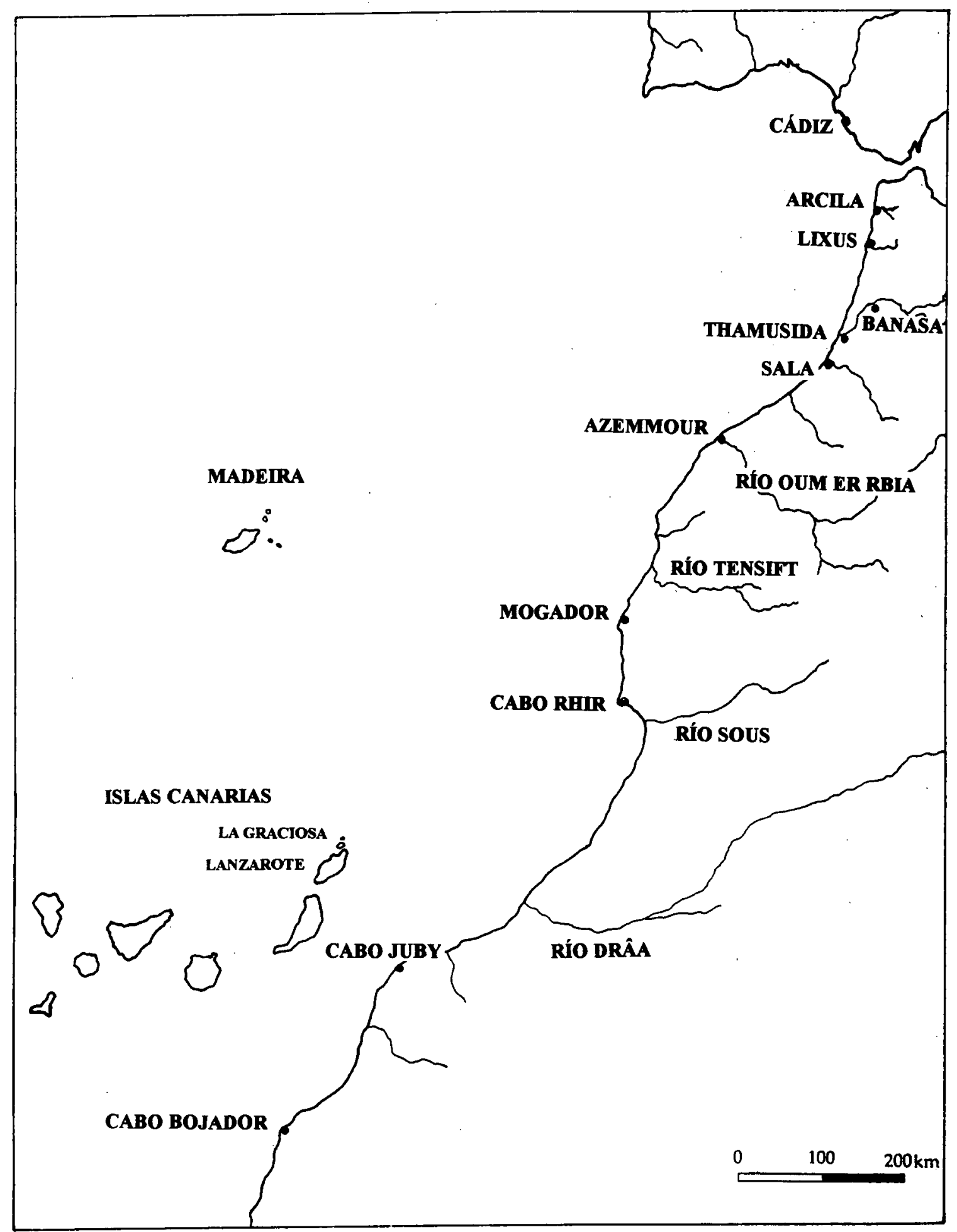

Fig. 3. Litoral Atlántico de Andalucía Occidental, Norte de África e Islas Canarias durante el Imperio Romano. Siglos I-V D.C. 